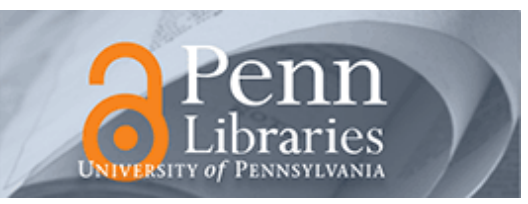

University of Pennsylvania

ScholarlyCommons

July 2007

\title{
Small Amplitude Reciprocating Wear Performance of Diamond- like Carbon Films: Dependence of Film Composition and Counterface Material
}

\author{
Jason A. Bares \\ University of Wisconsin \\ Anirudha V. Sumant \\ University of Wisconsin \\ David S. Grierson \\ University of Wisconsin \\ Robert W. Carpick \\ University of Pennsylvania, carpick@seas.upenn.edu \\ Kumar Sridharan \\ University of Wisconsin
}

Follow this and additional works at: https://repository.upenn.edu/meam_papers

\section{Recommended Citation}

Bares, Jason A.; Sumant, Anirudha V.; Grierson, David S.; Carpick, Robert W.; and Sridharan, Kumar, "Small Amplitude Reciprocating Wear Performance of Diamond-like Carbon Films: Dependence of Film Composition and Counterface Material" (2007). Departmental Papers (MEAM). 104.

https://repository.upenn.edu/meam_papers/104

Postprint version. Published in Tribology Letters, Volume 27, Issue 1, July 2007, pages 79-88.

Publisher URL: http://dx.doi.org/10.1007/s11249-007-9209-x

This paper is posted at ScholarlyCommons. https://repository.upenn.edu/meam_papers/104

For more information, please contact repository@pobox.upenn.edu. 


\title{
Small Amplitude Reciprocating Wear Performance of Diamond-like Carbon Films: Dependence of Film Composition and Counterface Material
}

\begin{abstract}
Small amplitude (50 $\mu \mathrm{m}$ ) reciprocating wear of hydrogen-containing diamond-like carbon (DLC) films of different compositions has been examined against silicon nitride and polymethyl-methacrylate (PMMA) counter-surfaces, and compared with the performance of an uncoated steel substrate. Three films were studied: a DLC film of conventional composition, a fluorine-containing DLC film (F-DLC), and siliconcontaining DLC film. The films were deposited on steel substrates from plasmas of organic precursor gases using the Plasma Immersion Ion Implantation and Deposition (PIIID) process, which allows for the non-line-of-sight deposition of films with tailored compositions. The amplitude of the resistive frictional force during the reciprocating wear experiments was monitored in situ, and the magnitude of film damage due to wear was evaluated using optical microscopy, optical profilometry, and atomic force microscopy. Wear debris was analyzed using scanning electron microscopy and energy dispersive spectroscopy. In terms of friction, the DLC and silicon-containing DLC films performed exceptionally well, showing friction coefficients less than 0.1 for both PMMA and silicon nitride counter-surfaces. DLC and silicon-containing DLC films also showed significant reductions in transfer of PMMA compared with the uncoated steel. The softer F-DLC film performed similarly well against PMMA, but against silicon nitride, friction displayed nearly periodic variations indicative of cyclic adhesion and release of worn film material during the wear process. The results demonstrate that the PIIID films achieve the well-known advantageous performance of other DLC films, and furthermore that the film performance can be significantly affected by the addition of dopants. In addition to the well-established reduction of friction and wear that DLC films generally provide, we show here that another property, low adhesiveness with PMMA, is another significant benefit in the use of DLC films.
\end{abstract}

\section{Keywords}

small amplitude reciprocating wear, diamond-like carbon films, plasma, friction

\section{Comments}

Postprint version. Published in Tribology Letters, Volume 27, Issue 1, July 2007, pages 79-88.

Publisher URL: http://dx.doi.org/10.1007/s11249-007-9209-x 
12

\title{
Small amplitude reciprocating wear performance of diamond-like carbon films: dependence of film composition and counterface material
}

\author{
Jason A. Bares ${ }^{\mathrm{a}}$, Anirudha V. Sumant ${ }^{\mathrm{a}, \mathrm{b}}$, David S. Grierson ${ }^{\mathrm{a}}$, Robert W. Carpick ${ }^{\mathrm{a}}$ and Kumar Sridharan ${ }^{\mathrm{a}, *}$ \\ ${ }^{a}$ Department of Engineering Physics, University of Wisconsin, 1500 Engineering Drive, Madison, WI, 53706, USA \\ ${ }^{b}$ Argonne National Laboratory, Argonne, IL, USA \\ ${ }^{c}$ University of Florida, Gainesville, FL, USA \\ ${ }^{d}$ Department of Mechanical Engineering and Applied Mechanics, University of Pennsylvania, Philadelphia, PA, USA
}

Received 29 May 2006; accepted 20 February 2007

\begin{abstract}
Small amplitude $(50 \mu \mathrm{m})$ reciprocating wear of hydrogen-containing diamond-like carbon (DLC) films of different compositions has been examined against silicon nitride and polymethyl-methacrylate (PMMA) counter-surfaces, and compared with the performance of an uncoated steel substrate. Three films were studied: a DLC film of conventional composition, a fluorinecontaining DLC film (F-DLC), and silicon-containing DLC film. The films were deposited on steel substrates from plasmas of organic precursor gases using the Plasma Immersion Ion Implantation and Deposition (PIIID) process, which allows for the nonline-of-sight deposition of films with tailored compositions. The amplitude of the resistive frictional force during the reciprocating wear experiments was monitored in situ, and the magnitude of film damage due to wear was evaluated using optical microscopy, optical profilometry, and atomic force microscopy. Wear debris was analyzed using scanning electron microscopy and energy dispersive spectroscopy. In terms of friction, the DLC and silicon-containing DLC films performed exceptionally well, showing friction coefficients less than 0.1 for both PMMA and silicon nitride counter-surfaces. DLC and silicon-containing DLC films also showed significant reductions in transfer of PMMA compared with the uncoated steel. The softer F-DLC film performed similarly well against PMMA, but against silicon nitride, friction displayed nearly periodic variations indicative of cyclic adhesion and release of worn film material during the wear process. The results demonstrate that the PIIID films achieve the well-known advantageous performance of other DLC films, and furthermore that the film performance can be significantly affected by the addition of dopants. In addition to the well-established reduction of friction and wear that DLC films generally provide, we show here that another property, low adhesiveness with PMMA, is another significant benefit in the use of DLC films.
\end{abstract}

KEY WORDS: small amplitude reciprocating wear, diamond-like carbon films, plasma, friction

\section{Introduction}

Diamond-like carbon (DLC) films have attracted considerable attention in research and commercial arenas because they possess a unique combination of properties including high hardness, low friction, chemical inertness, biocompatibility, hydrophobicity, high electrical resistivity, and high transparency to visible and infrared wavelengths [1-3]. Examples of present and potential applications of DLC films include coatings for manufacturing tools, magnetic storage devices, microelectromechanical systems (MEMS), scratch-resistant glasses and lenses, razor blades, and prosthetic devices [4-8]. DLC films are synthesized by ion- or plasmabased processes using hydrocarbon precursor gases and therefore contain substantial amounts of hydrogen (usually 10-50 atomic\%). Techniques for DLC film deposition include direct ion beam processes, plasmaenhanced chemical vapor deposition, and electron

*To whom correspondence should be addressed. E-mail: kumar@engr.wisc.edu cyclotron resonance CVD processes [1, 9-11]. DLC films are amorphous with no long-range order, and the carbon is present in both the hybridized $\mathrm{sp}^{3}$ (diamond) and $\mathrm{sp}^{2}$ (graphite) bonding configurations, although $\mathrm{sp}^{1}$ (polymeric) configuration has also been observed. The $\mathrm{sp}^{3} / \mathrm{sp}^{2}$ ratio, which strongly influences film properties, depends on the hydrogen content of the film and the deposition parameters, such as pressure, ion impingement energy, and the surface power density at the substrate $[12,13]$.

The tribological characteristics of DLC films have been the subject of a large number of investigations because of the high hardness and low friction that these films generally possess [14-18]. A wide range of results has been reported because of differences in methods of synthesis, film structure, and thickness, and test environment and procedures. Almost all macro-tribological studies on DLC films have been performed using pinon-disk or conventional high displacement reciprocating wear testers. Relatively few studies have been performed on DLC films under small amplitude wear conditions 
(fractions of a micrometer to a few $100 \mu \mathrm{m}$ ) and/or at relatively high reciprocating frequencies $(10-100$ s of $\mathrm{Hz})$ [19-22]. This type of wear usually occurs as a result of an unintended vibrations and is quite prevalent in many industrial applications such as aircraft, press-fit prosthetic devices, electrical contacts, nuclear reactors, and automobiles. The wear mechanisms in small amplitude reciprocating wear conditions are fundamentally different in many respects from unidirectional and high displacement reciprocating wear [23-26]. The localized concentration of wear in a small region can lead to the accumulation of wear debris and environmental reaction products in the relatively small region of the wear scar. Moreover, the sliding velocities can be very high and heat transfer is limited due to the small affected region. A strong dependence of friction on sliding velocity even in the regimes, achievable by conventional reciprocating wear testers has been recently demonstrated for DLC films [27-29], and the sliding velocity attained during small amplitude, high frequency reciprocating wear can be significantly higher than the velocities used in that study. This motivates the study of DLC films under small amplitude sliding conditions.

DLC films are often modified to improve their tribological performance by incorporating other elements, thus altering not only the composition but also the structure of the films. For example, compressive stresses adversely affect the tribological performance of DLC [30], and addition of metallic phases (e.g., W, Ta) to the film, as well as the use of a metallic interlayer, mitigates the sensitivity of tribological characteristics to compressive stresses [31]. This also reduces the sensitivity to humidity [31].

It is desirable to mitigate the effect of humidity, and to lower the adhesiveness and wettability of DLC, particularly for small-scale applications where capillary condensation and adhesion become critical $[32,33]$. The addition of $\mathrm{F}$ or $\mathrm{Si}$ to the DLC network structure not only lower the surface energy and wettability of DLC [34-38] but also influences the tribological characteristics $[16,31,34-36,39]$. The reduction of surface energy by the addition of $\mathrm{F}$ is attributed to the presence of $\mathrm{CF}_{2}$ and $-\mathrm{CF}_{3}$ groups [34, 38-41]. However, higher fluorine contents lead to a decrease in hardness, approaching the properties of poly-tetra-fluoro-ethylene (PTFE) [34, 38-41]. The deposition parameters, in addition to the fluorine content, dictate its wear resistance. The addition of silicon reduces the surface energy, possibly by decreasing the dispersive component of surface energy [31, 34]. As well, Si addition increases the hardness of the DLC films by promoting $\mathrm{sp}^{3}$ carbon hybridization [42-44].

The objective of this study was to examine the small amplitude reciprocating wear performance of DLC films synthesized from acetylene plasma, and fluorine-containing and silicon-containing DLC films synthesized using plasmas of acetylene mixed with tetra-fluoro-ethane and hexa-methyl-disiloxane, respectively. The former adds $F$ to the DLC film, while the latter adds both $\mathrm{Si}$ and $\mathrm{O}$. The fluorine- and silicon- containing carbon films can also be referred to as fluorocarbon films and $\mathrm{C}-\mathrm{Si}-\mathrm{O}$ films, respectively. However, the terms F-DLC and Si-DLC will be used in this paper, consistent with terminology used in studies on similar films [16, 34, 38]. Small amplitude reciprocating wear testing of these DLC films was performed against hard silicon nitride and soft PMMA counter-surfaces to capture a range of wear damage effects from abrasive material removal to counterface material adhesion and build-up. The findings of this study are expected to be of general relevance to applications such as manufacturing tools and components, MEMS devices, hard disks, and even nanomechanical data storage, for which DLC coatings may play a highly practical role in alleviating tribologicalrelated failures. While we do not attempt to match length scales, stresses, and velocities for any of these applications specifically, the smaller length scale and reciprocating nature of our wear tests, in contrast to conventional pin-on-disk testing, is a useful step toward the smaller length-scales and confined geometries that are found in the aforementioned applications.

\section{Experimental methodology}

\subsection{Plasma-based deposition of DLC films}

The three carbon-based films investigated in this study, a DLC, a fluorine-containing diamond-like carbon (F-DLC), and a silicon-containing diamond-like carbon (Si-DLC), were deposited using the Plasma Immersion Ion Implantation and Deposition (PIIID) process [45-49]. The PIIID process is inherently nonline-of-sight in nature and allows for uniform surface treatment of 3-dimensional parts without the necessity of part manipulation in the vacuum chamber during the surface treatment. The process does not require active heating of the sample being coated, minimizing thermal mismatch stresses and enabling the coating of thermallysensitive materials. It also allows for in situ substrate cleaning prior to deposition by, for example, Ar ion sputtering, and for the creation of an adhesion-promoting layer by ion implantation into the substrate prior to film deposition.

For this study, AISI 4140 steel samples were polished with a wet grinder by progressively using 240, 320, 400, and 600 grit silicon-carbide abrasive and then subjected to a final polishing step using $1 \mu \mathrm{m}$ diamond paste. Prior to being introduced into the plasma chamber, the samples were cleaned ultrasonically using acetone and alcohol. Once in the PIIID system, the samples were cleaned using an $\mathrm{Ar}^{+}$plasma in a glow discharge mode at a pressure of $12 \mathrm{mT}$ Torr using a stage bias of $-5 \mathrm{kV}$ 
182 for approximately $5 \mathrm{~min}$ to remove any traces of con183 taminants and native oxides. The DLC films were then 184 deposited using a plasma of acetylene precursor gas at a 185 pressure of $10 \mathrm{mT}$ Torr and a stage voltage bias of $-5 \mathrm{kV}$. 186 The Si-DLC films were deposited using a plasma of 187 hexa-methyl-disiloxane precursor gas at a pressure or $18815 \mathrm{mT}$ Torr and a stage voltage bias of $-3 \mathrm{kV}$. This oxy189 gen-containing precursor gas leads to the incorporation 190 of oxygen into the film along with silicon. The F-DLC 191 films were deposited using a plasma of a mixture of 192 acetylene and tetra-fluoro-ethane gases (4:1 ratio) at a 193 pressure of $15 \mathrm{mT}$ Torr and a stage voltage bias of $-3 \mathrm{kV}$. 194 The samples were cooled during film deposition by the 195 flow of coolant oil through the sample stage. The 196 thickness of the deposited films (as measured by profil197 ometry on semi-masked silicon coupons that were also 198 placed in the system) was in the range of $1-1.5 \mu \mathrm{m}$ 199 applied to the actuator, a measure of the average power per cycle expended by frictional processes is determined. This power is directly proportional to the force required to move the contacting stylus against the flat sample in an oscillatory motion and thus incorporates the effects of friction and any other dissipative forces during the wear process. We conservatively report the measured raw signal and label this as "Measured Resistive Force (arb. units)". The absolute scale of this signal is the same for all data presented here. In addition, the calibration of this measured signal against published friction coefficients is also measured, and discussed further below. Based on multiple tests performed with this instrument, the calibration provides a reasonable estimate of the actual friction coefficients. Details of the design and construction of this instrument are given elsewhere [19, 50].

The wear tests were performed under an applied load of $0.196 \mathrm{~N}$ and stylus displacement amplitude of $50 \mu \mathrm{m}$. This corresponded to a nominal Hertzian contact pressure of $\sim 620 \mathrm{MPa}$ for the silicon nitride stylus, and $\sim 50 \mathrm{MPa}$ for the PMMA stylus, roughly calculated by assuming a Young's Modulus of $180 \mathrm{GPa}$ for the DLC films. Tests were performed for 20,000 cycles. Additionally, tests for DLC and Si-DLC against PMMA countersurfaces were also performed up to 100,000 cycles to examine PMMA build-up at larger total sliding distances. The oscillation frequency was maintained at $37 \mathrm{~Hz}$, which is close to the resonant frequency, which allowed for continuous monitoring of the resistive frictional force at $1 \mathrm{~s}$ intervals. All tests were conducted in duplicate under dry sliding conditions in ambient air (relative humidity $\sim 50 \%$ ).

\subsection{Characterization of wear damage}

The wear damage and debris on the three DLC films and the control steel sample were imaged using optical microscopy and optical profilometry using a scanning white light interferometer (Zygo Corp., Middlefield, CT). Wear scars on the flat samples were imaged by AFM in contact mode. The SPIP software program was used to analyze AFM data, and a custom MatLab software routine was used to analyze both the optical profilometry and AFM data. These are used to calculate the wear volume for tests against the silicon nitride counter-surface, and the volume of polymer debris build-up for tests against the PMMA counter-surface. Wear scars on the PMMA and silicon nitride styli were not observable by optical microscopy; therefore, no measurement of the stylus wear volume could be made. Chemical analysis of wear debris was carried out by energy dispersive spectroscopy (EDS) in a scanning electron microscope (SEM) (JEOL JSM 6400, JEOL Ltd., Waterford, VA). 
Table 1

Summary of the surface roughness, microhardness, and small amplitude reciprocating damage volume for the uncoated steel and the DLC films.

\begin{tabular}{lcclcc}
\hline Material & $\begin{array}{l}\mathrm{R}_{\mathrm{q}} \\
(\mathrm{nm})\end{array}$ & $\begin{array}{l}\text { Hardness } \\
\left(\mathrm{HK}, \mathrm{kg} / \mathrm{mm}^{2}\right)\end{array}$ & $\begin{array}{l}\text { Wear volume* } \\
\left(\mathrm{mm}^{3}\right)\end{array}$ & $\begin{array}{l}\text { Wear rate* } \\
\left(\mathrm{mm}^{3} \mathrm{~N}^{-1} \mathrm{~m}^{-1}\right)\end{array}$ & $\begin{array}{l}\text { Debris volume** } \\
\left(\mathrm{mm}^{3}\right)\end{array}$ \\
\hline Steel & 4 & $300 \pm 50$ & $\mathrm{~N} / \mathrm{A}$ & $3.1 \times 10^{-8}$ & $>>4.8 \times 10^{-7}$ \\
DLC & 6 & $1300 \pm 100$ & $2.6 \times 10^{-8}$ & $6.6 \times 10^{-8}$ & $9.5 \times 10^{-9}$ \\
Si-DLC & 11 & $1400 \pm 200$ & $1.7 \times 10^{-7}$ & $2.7 \times 10^{-8}$ & $>4.4 \times 10^{-7}$ \\
F-DLC & 6 & & N/A & $2.1 \times 10^{-7}$ & $>1.0 \times 10^{-6}$ \\
\hline
\end{tabular}

* Wear volume refers to volume of material lost from sample after tests against silicon nitride stylus.** Debris volume refers to volume of polymer build-up on sample after tests against PMMA stylus.

\section{Results and discussion}

Table 1 summarizes the results of the wear volume and polymer debris volume measurements as well as surface roughness and microhardness of the materials used in this study. Wear volume in table 1 refers to volume removed for each sample (steel or DLC film) in tests using the silicon nitride countersurface, while debris volume refers to the extent of polymer build-up on each sample in tests using the PMMA countersurface. While the steel surface is initially very smooth $(4 \mathrm{~nm}$ RMS roughness), all three DLC films are rougher. This is likely the result of substrate roughening due to the Ar ion sputtering performed prior to deposition.

Due to the incorporation of substrate effects, the hardness values reported are underestimated as they represent a composite hardness of the film-substrate system. They simply provide a means of gauging the relative film hardness. Most notably, the composite hardness of the DLC and Si-DLC coatings on steel are high (in excess of $1000 \mathrm{HK}$ ). These values are compa- rable to those obtained in other studies of DLC and $\mathrm{Si}$ DLC. Savvides and Bell measured hardness of DLC films using an ultralow-load microhardness tester and found values ranging from 12 to $30 \mathrm{GPa}$ while varying film deposition parameters [51]. Achanta, Drees, and Celis reported a hardness of $24.7 \mathrm{GPa}$ for DLC as measured by nanoindentation [52]. Varma, Palshin, and Meletis measured the microhardness of Si-DLC films using a Knoop indenter ( $0.1 \mathrm{~N}$ load) and found hardness values of $11.2-17.3 \mathrm{GPa}$ for various processing conditions [43]. However, the F-DLC coating on steel is significantly softer, with the composite hardness comparable to that of the base steel. Although, a wide range of hardness values have been reported for F-DLC films of different compositions and preparation methods [53-55], hardness results from this study are comparable to those obtained by Hatada and Baba [54].

Optical micrographs of the wear damage on the three films and steel samples after testing with the silicon nitride counter-surface are shown in figure 1, and the wear
306

307

308

309

310

311

312

313

314

315

316

317

318

319

320

321

322

323

324

325
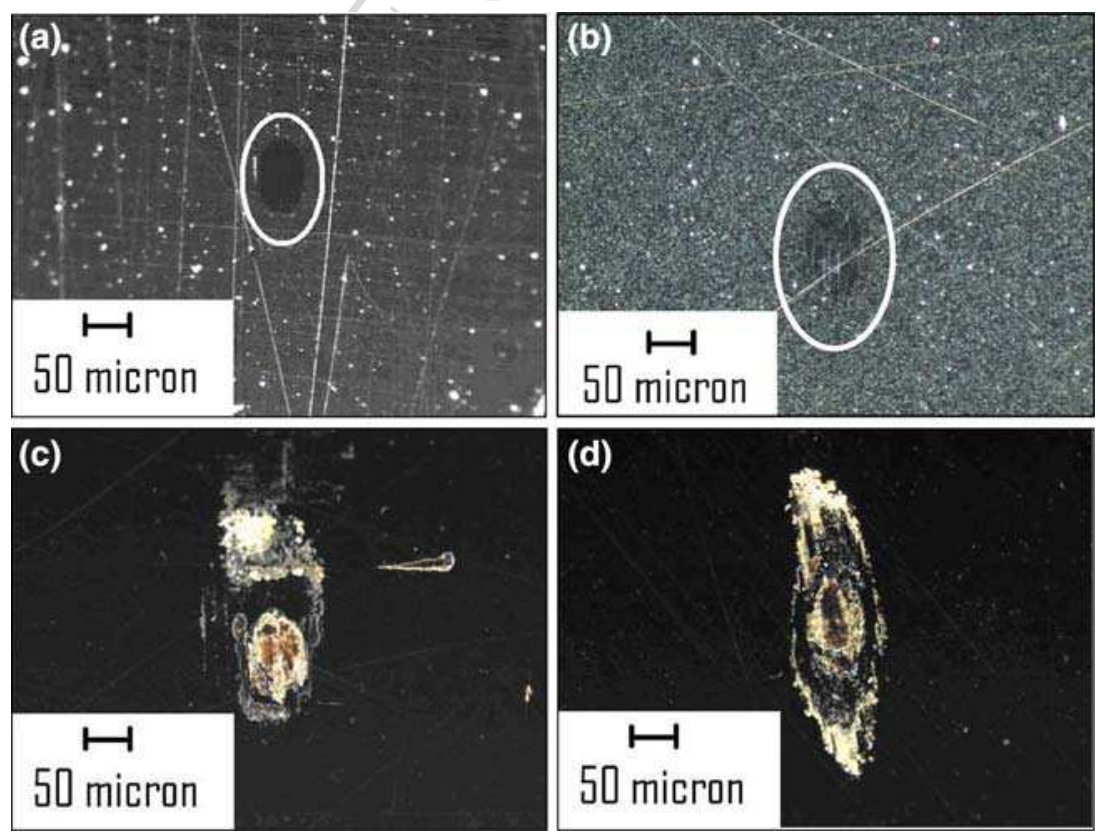

Figure 1. Dark field optical micrographs of wear scars on DLC films and uncoated steel produced by small amplitude reciprocating wear against a silicon nitride counter-surface: (a) DLC, (b) Si-DLC, (c) F-DLC, and (d) uncoated steel. The scars on DLC and Si-DLC films have been circled for clarity. 
volumes reported in table 1. The wear scars for DLC and Si-DLC films, shown in figures $1 \mathrm{a}$ and $\mathrm{b}$ respectively, reveal an impressively small wear volume and little or no observable wear debris. These two films showed no evidence of fracture or breakthrough at the coating-substrate interface. The F-DLC film, shown in figure $1 \mathrm{c}$, exhibited a much larger wear scar and more wear debris generation. Furthermore, the wear rate was rapid enough for breakthrough to occur at the filmsubstrate interface as evidenced by the reddish region of oxidized steel at the bottom the wear scar. This suggests that the wear debris contain oxidized steel particles in addition to F-DLC particles. An SEM image of the F-DLC wear scar along with corresponding EDS dot map for oxygen are shown in figure 2, confirming that film breakthrough occurred, and the underlying steel substrate oxidized. This is consistent with the low microhardness of this film and shows the F-DLC film is not able to provide adequate abrasive wear resistance. EDS analysis of the F-DLC wear track also showed the presence of silicon, from wear of the silicon nitride stylus, and chromium, from wear of the 4140 steel substrate. The wear scar formed on the uncoated control steel, shown in figure $1 \mathrm{~d}$, is substantially larger than that on any of the carbon films, and exhibits evidence of surface oxidation and wear debris generation. AFM and optical profilometry (not shown) reveal a build-up of material in the wear track, indicating that steel debris particles had oxidized, as expected, and confirmed by EDS (figure 2). Low concentrations of silicon, derived from the silicon nitride stylus, were also detected in the wear track region.

AFM images of the wear scars from testing against silicon nitride support the observations in figure 1. Both DLC and Si-DLC (figure 3a) exhibit very little material loss and show negligible wear debris. The approximate wear volume of the DLC wear scar is $2.6 \times 10^{-8} \mathrm{~mm}^{3}$ while the wear volume of the Si-DLC wear scar was higher at $1.7 \times 10^{-7} \mathrm{~mm}^{3}$ (table 1). This corresponds to wear rates of $6.6 \times 10^{-8} \mathrm{~mm}^{3} \mathrm{~N}^{-1} \mathrm{~m}^{-1}$ and $4.4 \times$ $10^{-7} \mathrm{~mm}^{3} \mathrm{~N}^{-1} \mathrm{~m}^{-1}$ for DLC and Si-DLC, respectively. For comparison, a wear rate of $2.5 \times 10^{-8} \mathrm{~mm}^{3} \mathrm{~N}^{-1} \mathrm{~m}^{-1}$ was found for pin-on-disk testing of silicon nitride on DLC in dry air by Jia et al. [56]. Kim, Fischer, and Gallois also performed pin-on-disk testing of the same material system and found higher wear rates $\left(\sim 10^{-7} \mathrm{~mm}^{3} \mathrm{~N}^{-1} \mathrm{~m}^{-1}\right)$ for $50 \%$ RH air [57]. The F-DLC and uncoated steel surfaces show a build-up rather than a loss of material in the most severely worn areas. This build-up is a manifestation of film wear, smearing, delamination, oxidation of the underlying steel in the case of F-DLC, and wear and oxidation for the uncoated steel. For the F-DLC film, a considerable amount of wear debris resides throughout the wear scar, whereas for the uncoated steel the wear debris is pushed towards the sides of the wear scar due to the force of the moving stylus. As a result of this stochastic build-up due to wear products, smearing effects, and oxidation, the calculated wear volumes for the F-DLC and steel samples are not representative of their actual wear behavior. The calculations of "volume removed" and "debris volume" were also influenced by AFM scanning artifacts resulting from the topography of the debris. Thus, wear rates for these samples were not reported due to inaccuracy.

Figure 4 shows the variation in frictional force amplitude (raw signal units) against a silicon nitride counter-surface over the course of a 20,000 cycle reciprocating wear test for all four samples. The uncoated steel consistently exhibited the highest friction force. DLC and Si-DLC films demonstrated significantly lower friction forces than the uncoated steel, while the F-DLC film exhibited a coarsely periodic variation with the peak friction force approaching the values of steel, and then lowering to a minimum value of approximately half that of steel. This undulating behavior is indicative of thirdbody wear processes involving material removal and subsequent smearing of the wear debris, and is consistent with the optical microscopy, optical profilometry, and AFM images of the wear scar discussed earlier. The partially polymeric nature of F-DLC may lead to the formation of a transfer film between the stylus and sample which is periodically created and detached from the wear surface, causing substantial variations in friction.

Optical micrographs of the wear scars on all three films and uncoated steel after testing against PMMA are shown in figure 5. The DLC film in figure $5 \mathrm{a}$ and the Si-DLC film in figure $5 \mathrm{~b}$ show negligible amounts of PMMA debris, and this debris is observed predominantly on the sides of the wear scar while the interior of the wear scar remains free of any polymer build-up. The exclusion of wear debris to the extremities of the wear scar indicates that PMMA does not have a propensity to adhere strongly to these films. The F-DLC film shows PMMA build-up in the interior of the wear track, as shown in figure $5 \mathrm{c}$, but much of the debris is pushed towards the sides of the wear scar due to the low surface energy of this film. However, the greater amount of wear debris is likely due to the low hardness of this film. In contrast, the uncoated steel sample in figure $5 \mathrm{~d}$ showed excessive amounts of PMMA at the ends of the wear scar and also its accumulation throughout the interior of the scar.

AFM images of the wear tracks formed by PMMA counter-surfaces showed varying amounts of polymer and wear debris build-up on each film. Consistent with the optical micrographs shown in figure 5, AFM measurements showed substantially larger amounts of PMMA build-up and wear for the F-DLC film and uncoated steel compared to DLC and Si-DLC (figure $3 b$ ). The debris volume for F-DLC may be 


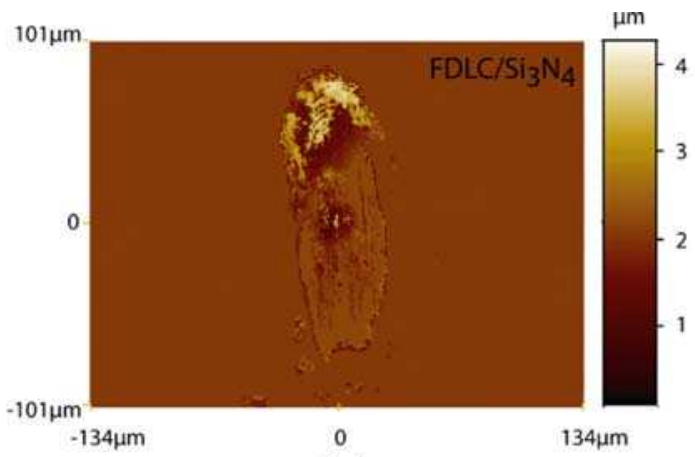

(a)

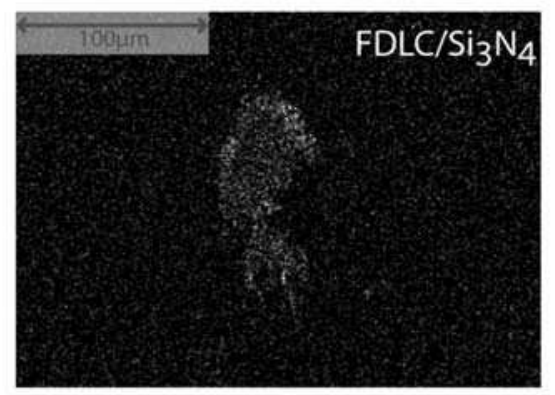

(c)

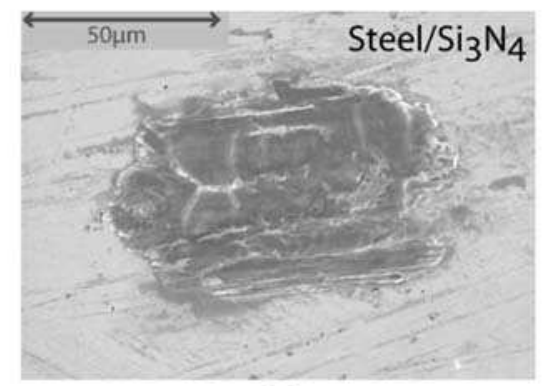

(e)

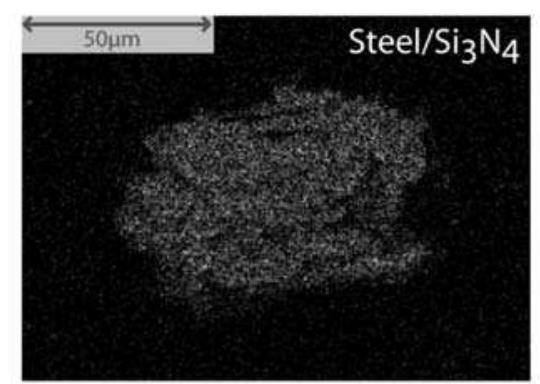

(g)

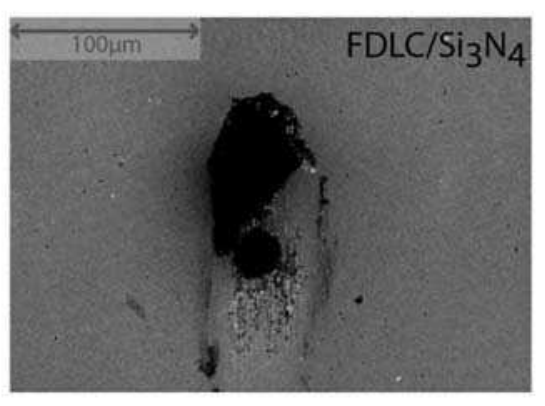

(b)

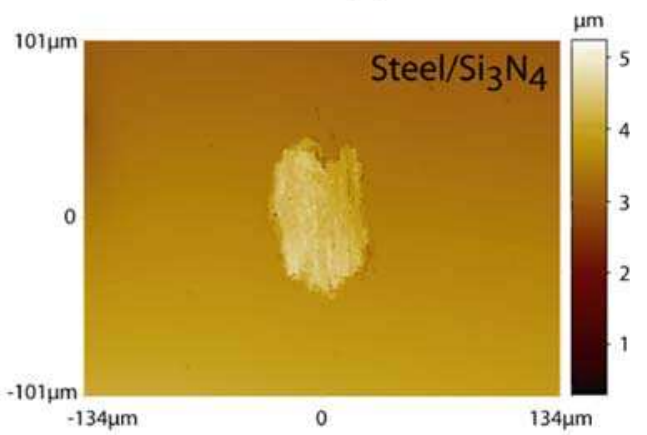

(d)

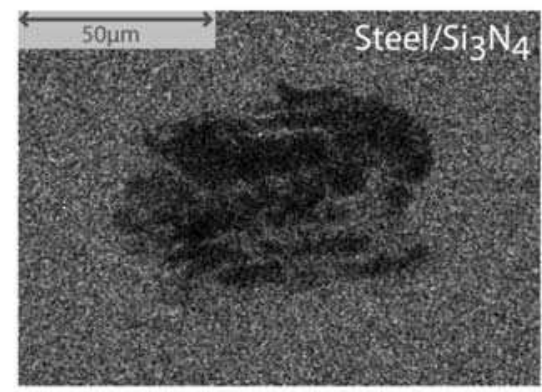

(f) somewhat overestimated due to the wearing of the film itself, which is much softer than the either DLC or Si-DLC. Also, the Si-DLC exhibits greater adhesion and build-up of PMMA than DLC, despite its lower surface energy [38]. Adhesion is affected by interfacial interactions as well as the surface energy, and interactions between oxygen groups in both the PMMA and the Si-DLC could contribute to this effect [58], or this could 


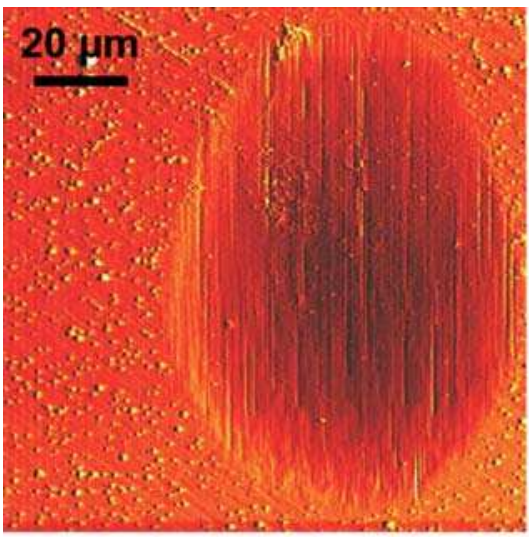

(a)

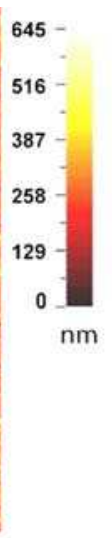

(b)

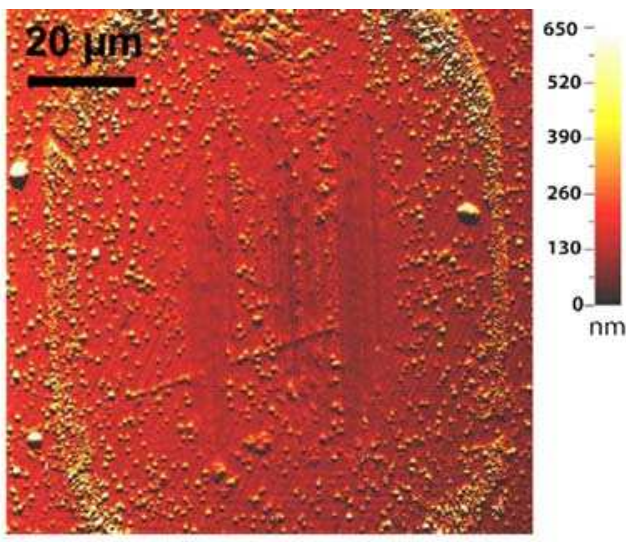

Figure 3. AFM images of wear scars on the Si-DLC films produced by small amplitude reciprocating wear against (a) silicon nitride and (b) PMMA counter-surface.

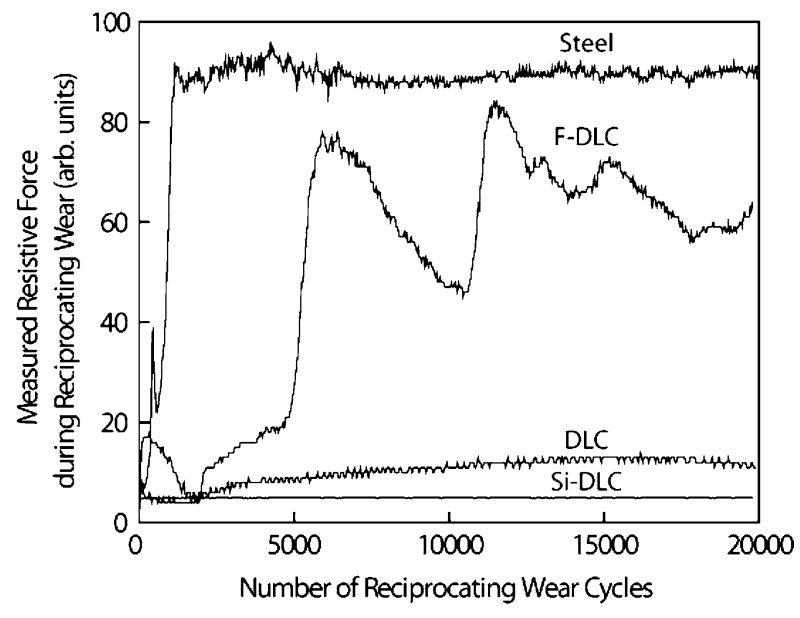

Figure 4. Plot of measured resistive force versus number of reciprocating cycles for wear tests against silicon nitride counter-surface.

simply be a result of the higher initial roughness of the Si-DLC film. The RMS roughness on DLC, F-DLC, and Si-DLC films deposited on semiconductor grade $\mathrm{Si}$ wafers were measured to be $\sim 0.3, \sim 0.5$, and $\sim 1.0 \mathrm{~nm}$, respectively, over a $1 \times 1 \mu \mathrm{m}$ area using Atomic Force Microscopy. The amount of polymer debris on the surface of each sample is listed in table 1. For all samples except the DLC film, small amounts of debris existed outside the field of view used in debris volume calculations for the coatings; therefore, debris volumes listed in table 1 underestimate the actual amount of debris on the film surfaces. For example, the total amount of polymer debris on the steel surface including all debris outside the wear track could not be measured. The interior of the wear scar alone had a debris volume of $4.8 \times 10^{-7} \mathrm{~mm}^{3}$, so the total debris volume, including debris outside the field of view, is much greater than this amount and far greater than that for any of the three films.

Figure 6 shows the trends in frictional force amplitude (raw signal units) as a function of the number of cycles for all four samples when sliding against PMMA. Once again, all films displayed lower friction forces than the uncoated steel. The higher friction force for the steel is consistent with adhesion and build-up of a PMMA film on the steel surface, as observed in the optical microscope, optical profilometry, and AFM images. The F-DLC does not exhibit the undulating trend observed with the silicon nitride counterface. This is likely because of the relatively low hardness of PMMA. DLC and Si-DLC exhibited comparably low friction forces that remained relatively constant throughout the wear tests.

For the DLC and Si-DLC films, additional tests were performed for 100,000 cycles with the goal of inducing PMMA adhesion on these surfaces, which in turn would lead to a higher friction force. However, friction force data and imaging of the wear scars verified that increasing the sliding distance had no effect on the friction force or the amount of polymer build-up on the film surface.

To correlate the coefficient of friction with the measured raw friction force signal, small amplitude reciprocating wear tests were performed with the same instrument for several common material pairs whose coefficient of friction values are documented extensively in literature. These material pairs were tested under the same conditions as the three films and the steel sample. Figure 7a shows the average measured raw friction force signal along with published coefficient of friction values for these material pairs. For certain material pairs, a range of friction coefficients are shown based literature sources that were reviewed [59-64]. The plot does show a roughly linear trend, in that the friction force signal increases with increasing coefficients of friction. The lack of complete correlation suggests that other factors such as wear debris generation, three-body wear, and adhesion are also incorporated in the measurements, and the coefficient of friction alone does not determine the wear process. Nevertheless, this relates the friction 

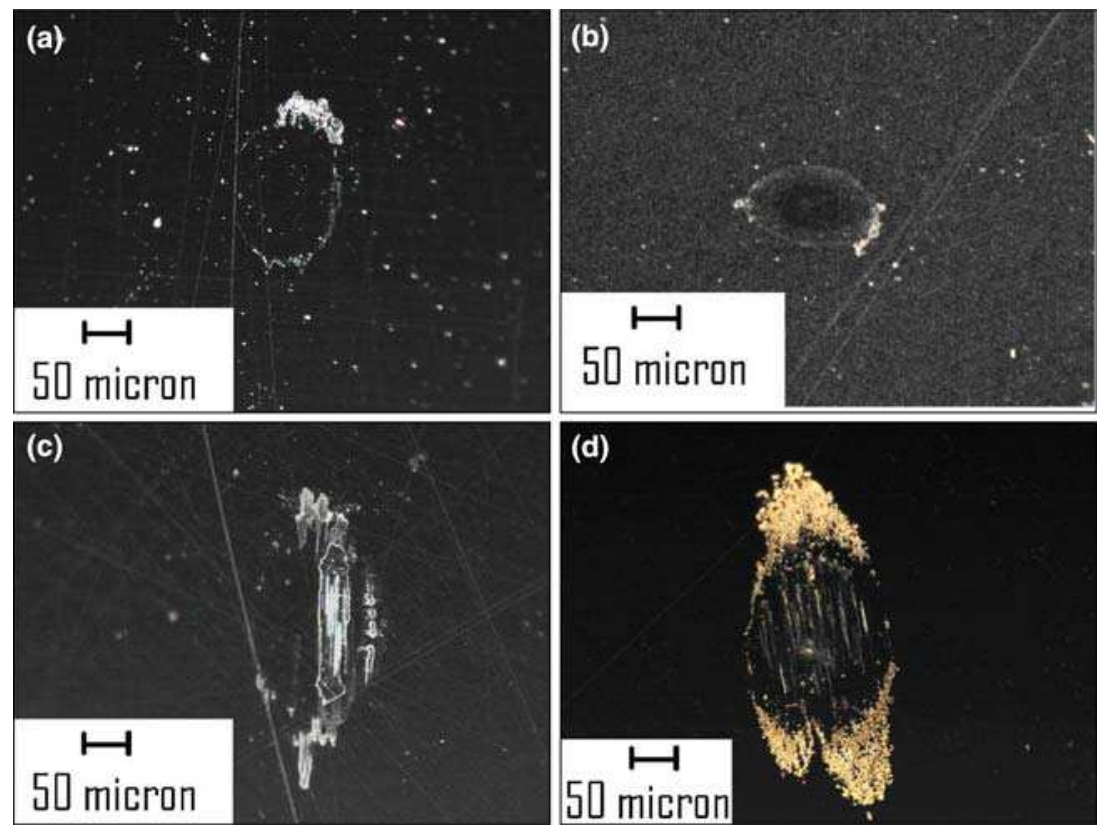

Figure 5. Optical micrographs of wear scars on DLC films and uncoated steel produced by small amplitude reciprocating wear against polymer PMMA counter-surface: (a) DLC, (b) Si-DLC, (c) F-DLC, and (d) uncoated steel.

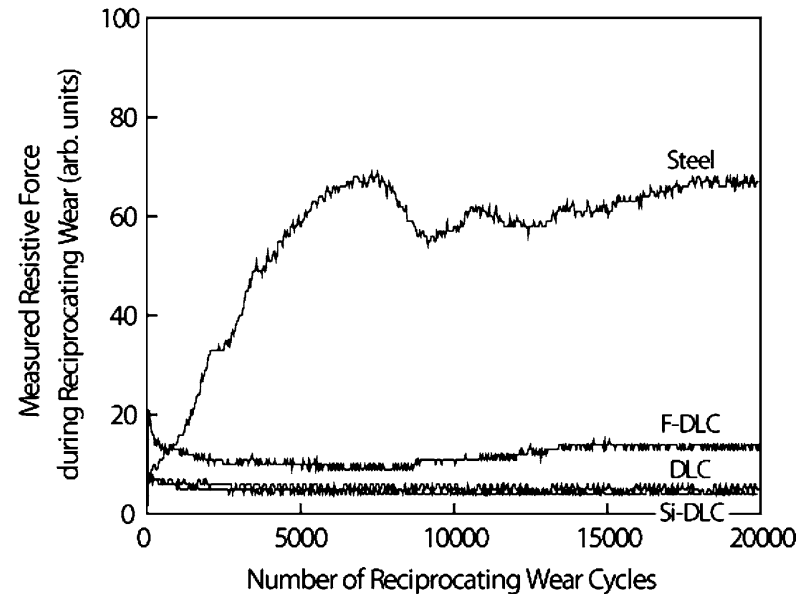

Figure 6. Plot of measured resistive force versus number of reciprocating cycles for wear tests against PMMA counter-surface.

force signal measured in the wear tests in this study with documented friction coefficients and allows us to ascribe approximate friction coefficients for the DLC films investigated in this study. The estimates of friction coefficients for the DLC films, as obtained from this plot and shown in figure $7 \mathrm{~b}$, indicate that these films have friction coefficients substantially lower than several common material pairs, and approach low coefficient of friction materials such as poly-tetra-fluoro-ethylene (PTFE).

The estimated friction coefficients from this study for DLC and Si-DLC against silicon nitride compare favorably with other published values. Jia et al. obtained a friction coefficient of $\sim 0.05$ for pin-on-disk

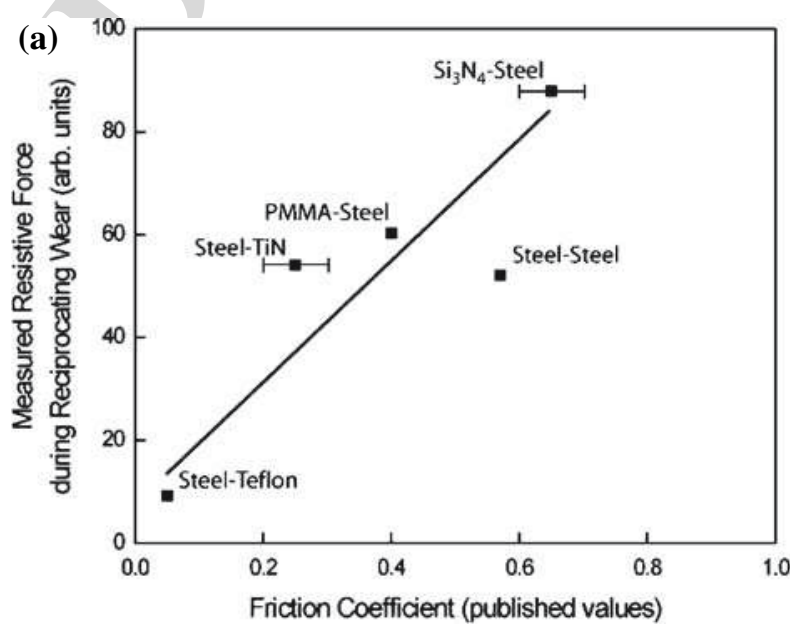

(b)

\begin{tabular}{|c|c|c|}
\hline Slider & Film & Estimated $\mu$ \\
\hline \multirow{4}{*}{$\mathrm{Si}_{3} \mathrm{~N}_{4}$} & DLC & 0.08 \\
\cline { 2 - 3 } & Si-DLC & 0.04 \\
\cline { 2 - 3 } & \multirow{2}{*}{ FDLC } & 0.65 \\
\cline { 3 - 3 } & & 0.35 \\
\hline \multirow{3}{*}{ PMMA } & DLC & 0.04 \\
\cline { 2 - 3 } & Si-DLC & 0.04 \\
\cline { 2 - 3 } & FDLC & 0.07 \\
\hline
\end{tabular}

Figure 7. (a) Plot of average resistive force measured against published values for coefficient of friction for five different material pairs [38-43]; (b) Table of estimated coefficients of friction based on the information in Fig. 7(a).

sliding of DLC against silicon nitride in dry air [56]. Kim, Fischer, and Gallois also investigated pin-on-disk sliding of $\mathrm{Si}_{3} \mathrm{~N}_{4}$ on DLC in various gaseous environments 
and reported a friction coefficient of 0.08 in air $(50 \%$ RH) [57]. Achanta, Drees, and Celis found a decrease in surface roughness of DLC films (quantified by AFM) with increasing number of reciprocating cycles in contact with a spherical silicon nitride counterbody, and reported a steady state friction coefficient of 0.1 in air $(0.10 \mathrm{~N}$ load, $400 \mu \mathrm{m}$ sliding amplitude at $0.2 \mathrm{~Hz}$ for 1000-5000 cycles) [52]. Drees, Celis, and Achanta reported friction coefficients of $\sim 0.19-0.25$ for reciprocating sliding of silicon nitride against DLC under similar conditions $(0.25 \mathrm{~N}$ load, $300 \mu \mathrm{m}$ sliding amplitude at $0.5 \mathrm{~Hz}$ for 1000 cycles) [22].

Few studies have been performed with polymeric counterbodies sliding against DLC films. Tsuchiya and Suzuki reported a friction coefficient of $\sim 0.18$ for PMMA sliding against metal-containing DLC films in a flat-on-flat configuration (2.6 $\mathrm{N}$ load, no reciprocation) [65]. He et al. used HDPE, which has properties similar to PMMA, as the pin material for pin-on-disc testing (1.5 N load, 120 cycles/min, 15,800 total cycles) of DLC-coated PMMA and reported a friction coefficient of $\sim 0.25$ and wear rate of $4.14 \times 10^{-8} \mathrm{~mm}^{3} \mathrm{~N}^{-1} \mathrm{~m}^{-1}$ in air $(15 \% \mathrm{RH})$ [66].

\section{Conclusions}

The small amplitude reciprocating wear behavior of a DLC film and fluorine-containing and silicon-containing DLC films deposited on steel using the PIIID process were evaluated against silicon nitride and PMMA counter-surfaces, and compared to the performance of uncoated steel. For abrasive wear conditions against silicon nitride, the DLC and Si-DLC films exhibited an extremely low wear volume, wear rate, and amount of debris generation, as well as a much lower frictional force as compared to the control steel sample. The softer F-DLC coating exhibited a higher wear volume, wear rate, and greater debris generation, and undulating trends in friction force indicate a cycling of material wear and smearing at the interface. For wear against the softer PMMA counter-surface, all three films exhibited lower adhesion, transfer, and build-up of PMMA compared to the control steel sample. The DLC and Si-DLC exhibited the least amount of PMMA build-up. A plot of the friction force signal against coefficients of friction for a range of known material pairs showed a linear trend, but a lack of complete correlation indicates that other factors in addition to coefficient of friction also dictate the wear process. Estimates from this calibration indicate that carbonbased films investigated in this study have coefficients of friction significantly lower than common material pairs and comparable to other high-performance DLC films.

Low friction, high hardness films such as those examined in this study have a wide range of potential applications in industry for manufacturing tools and components. Furthermore, the decreasing size scale of technology leads to increased influence of surface effects including friction, adhesion, and wear for small device applications. Thus, these types of films may hold promise for technologies such as MEMS devices, smallscale machining applications, and even nanomechanical data storage.

\section{Acknowledgments}

This work was supported by the Air Force Office of Scientific Research under contract number FA9550-051-0204. The authors are grateful to Mr. Perry Sandstrom of the University of Wisconsin for his assistance with the small amplitude reciprocating wear tester.

\section{References}

[1] B. Bhushan, Diamond Relat. Mater. 8 (1999) 1985.

[2] M.J. Mirtich, M.T. Kussmaul, B.A. Banks and J.S. Sovey, NASA Tech. Briefs 27-28 (1990) 1

[3] A.A. Voevodin, M.S. Donley, J.S. Zabinski and J.E. Bultman, Surf. Coat. Technol. 77 (1995) 534.

[4] T. Michler and K. Taube, Metal Form. (1998) 23.

[5] Advan. Mater. Process. 161 (2003) 8.

[6] Vac. Thin Films (1999) 16.

[7] G. Dearnaley, Clin. Mater. 12 (1993) 237.

[8] N.S. Tambe and B. Bhushan, J. Vac. Sci. Technol. - A 23 (2005) 830.

[9] A. Erdemir, F.A. Nichols, X.Z. Pan, R. Wei and P.J. Wilbur, Diamond Relat. Mater. 3 (1994) 119.

[10] K. Oguri and T. Arai, J. Mater. Res. 7 (1992) 1313.

[11] S. Anders, A. Anders and I.G. Brown, Plasma Sour. - Sci. Technol. 4 (1995) 1.

[12] B.K. Gupta and B. Bhushan, Wear 190 (1995) 110.

[13] K.J. Cuomo, D.L. Pappas, J. Bruley, J.P. Doyle and K.L. Seagner, J. Appl. Phys. 70 (1991) 1706.

[14] S. Sundararajan and B. Bhushan, Wear 225-229 (1999) 678.

[15] I.L. Singer, S.D. Dvorak, K.J. Wahl and T.W. Scharf, J. Vac. Sci. Technol. - A 21 (2003) 232.

[16] C. Donnet, J. Fontaine, A. Grill and T.L. Mogne, Tribol. Lett. 9 (2001) 137.

[17] F.E. Kennedy, D.L.A. Erdemir, J.B. Woodford and T. Kato, Wear 255 (2005) 854.

[18] J. Hershberger, O. Ozturk, O.O. Ajayi, J.B. Woodford, A. Erdemir, R.A. Erck and G.R. Fenske, Surf. Coat. Technol. 179 (2004) 237.

[19] P.W. Sandstrom, K. Sridharan and J.R. Conrad, Wear 166 (1993) 163.

[20] K. Schouterden, B. Blanpain, J.P. Cells and O. Vingsbo, Wear 181-183 (1995) 86.

[21] D. Klaffke and A. Skopp, Surf. Coat. Technol. 98 (1998) 953.

[22] D. Drees, J. Celis and S. Achanta, Surf. Coat. Technol. 188-189 (2004) 511.

[23] S.R. Brown, (ed). Materials Evaluation under Fretting Conditions (ASTM Special Technical Publications, USA, 1981) 780.

[24] R.B. Waterhouse, Fretting Corrosion (Pergamon, New York, 1971).

[25] P.L. Hurricks, Wear 30 (1974) 189.

[26] N.P. Suh, Wear 44 (1977) 1.

[27] J.A. Heimberg, K.J. Wahl, I.L. Singer and A. Erdemir, Appl. Phys. Lett. 78 (2001) 1.

[28] P. Dickrell, W. Sawyer and A. Erdemir, J. Tribol. 126 (2004) 615. 
[29] P. Dickrell, W. Sawyer, J. Heimberg, I. Singer, K. Wahl and A. Erdemir, Trans. ASME 127 (2005) 82.

[30] Q. Wei, J. Sankar and J. Narayan, Surf. Coat. Technol. 146-147 (2001) 250.

[31] M. Grischke, K. Bewilogua and H. Dimigen, Mater. Manufact. Process. 8 (1993) 407.

[32] M. Scherge, X. Li and J. Schaefer, Tribol. Lett. 6 (1999) 215.

[33] W. vanSpengen, R. Puers and I. DeWolf, J. Micromech Microeng 12 (2002) 702 .

[34] M. Grischke, K. Bewilogua, K. Trojan and H. Dimigen, Surf. Coat. Technol. 74-75 (1995) 739.

[35] C. Donnet, J. Fontaine, A. Grill, V. Patel, C. Jahnes and M. Belin, Surf. Coat. Technol. 94-95 (1997) 531.

[36] S.A. Visser, C.E. Hewitt, J. Fornalik, G. Braunstein, C. Srividya and S.V. Babu, Surf. Coat. Technol. 96 (1997) 210.

[37] J. Schwarz, M. Schmidt and A. Ohl, Surf. Coat. Technol. 98 (1998) 859.

[38] C.G. Fountzoulas, J.D. Demaree, W.E. Kosik, W. Franzen, W. Croft and J.K. Hiryonen, Mater. Res. Soc. Symp. Proc. 279 (1993) 645.

[39] C. Donnet, T.L. Mogne, L. Ponsonnet, M. Belin, A. Grill, V. Patel and C. Jahnes, Tribol. Lett. 4 (1998) 259.

[40] S. Miyake, I. Takahashi, H. Watanabe and H. Yoshihara, ASLE Trans. 30 (1987) 21.

[41] R.S. Butter, D.R. Waterman, A.H. Lettington, R.T. Ramos and E.J. Fordham, Thin Sol Films 311 (1997) 107.

[42] K.R. Lee, M.G. Kim, S.J. Cho, K.Y. Eun and T.Y. Seong, Thin Sol Films 308 (1997) 263-267.

[43] A. Varma, V. Palshin and E.I. Meletis, Surf. Coat. Technol. 148 (2001) 305 .

[44] X. He, K. Walter, M. Nastasi, S. Lee and M. Fung, J. Vac. Sci. Technol. A 18 (2000) 2143.

[45] A. Anders, (ed). Handbook of Plasma Immersion Ion Implantation and Film Deposition (John Wiley \& Sons, 2000).

[46] J.R. Conrad, U.S. Patent \#4764394 (1988).
[47] K. Sridharan, J.R. Conrad, F.J. Worzala and R.A. Dodd, Mater. Sci. Eng. - A 128 (1990) 259.

[48] K. Sridharan and R.R. Reeber, Advan. Mater. Process. 12 (1994) 21.

[49] D.J. Rej, Handbook of Thin Film Processing Technology, Plasma Immersion Ion Implantation (IOP Publishing Ltd., Bristol, 1996).

[50] P.W. Sandstrom, U.S. Patent \#5375451 (1994).

[51] N. Savvides and T. Bell, J. Appl. Phys. 72 (1992) 2791.

[52] S. Achanta, D. Drees and J. Celis, Wear 259 (2005) 719.

[53] M. Hakovirta, R. Verda, X. He and M. Nastasi, Diamond Relat. Mater. 10 (2001) 1486.

[54] R. Hatada and K. Baba, Nuc. Instrum. Met. Phys. Res. B 148 (1999) 655.

[55] G. Yu, B. Tay and Z. Sun, Surf. Coat. Technol. 191 (2005) 236.

[56] K. Jia, Y. Li, T. Fischer and B. Gallois, J. Mater. Res/ 10 (1995) 1403.

[57] D. Kim, T. Fischer and B. Gallois, Surf. Coat. Technol. 49 (1991) 537.

[58] J.N. Israelachvili, Intermolecular and Surface Forces 2nd ed. (Academic Press, London, 1991).

[59] I.L. Singer, S. Fayeulle and P.D. Ehni, Wear 149 (1991) 375.

[60] I. Grigoriev, E. Meilikhov, (eds). CRC Handbook of Physical Quantities (CRC Press, 1996)

[61] L. Tuchinskiy, E. Veksler, R. Loutfy and M. Williams, Tribol. Trans. 43 (2000) 603

[62] C.C. Liu and J.L. Huang, Mater. Sci. Eng. - A 384 (2004) 299.

[63] Plastics Design Library, Fatigue and Tribological Properties of Plastics and Elastomers (William Andrew Publishing, New York, 1995).

[64] H. Holleck, J. Vac. Sci. Technol. - A 4 (1986) 2661

[65] F. Tsuchiya and H. Suzuki, e-J. Surf. Sci. Nanotechnol. 3 (2005) 421.

[66] X. He, K. Walter, M. Nastasi, S. Lee and X. Sun, Thin Sol. Films 355-366 (1999) 167. 